\title{
Reducing the Time of Heat Treatment Cycle of the Manganese Steel
}

\author{
Arvind Kumar
}

\begin{abstract}
Manganese steels (Hadfield) have a wide application/requirement in industries because of their respectable resistance to wear, great hardening capacity for work, as well as high hardness and ductility. The customary heat treatment for these steels is defined as the solution of annealing and cooling in a water bath. This heat treatment has the objective of eliminating carbides and has many costs because it requires a stretched time of operation. Within the current research, 5 different heat treatment cycles have been evaluated to achieve shortest \& undeviating possible time with the proper structure without carbide. The microstructure/grained structure \& impact energy of samples with different thermal treatments were investigated. The concluded outcomes illustrates that, the best cycle is to austenite at $1080{ }^{\circ} \mathrm{C}$ with a certain maintenance rate and time of 2 hours and then quench in water, so it consume less time \& the finishing structure is completely austenite.
\end{abstract}

Keywords: heat treatment, Austenitizing time, manganese austenite steel, austenitizing temperature, quenching time.

\section{INTRODUCTION}

Austenite manganese steel (AMS) was first explored by Robert Hadfield in year of 1882. These steels are famous in industries because of their particular specification as good wear resistance between high hardness \& worthy ductility \& high workability. Its main composition includes 1 to $1.4 \%$ carbon, 10 to $14 \%$ manganese with a ratio of 1 to 10 [1]-[3]. In the parts that are theme to strong blows and to the wear in the type of groove as hammers, it would be preferred to use 10.5 to 11 (means smaller carbons) and for those that are exposed to pressure and wear (such as abrasions) such as jaws and concave it is the preferred range of 10 to 10.5 (more carbons). Today, the main consumers of cast iron parts prepared of Hadfield steel are the mining, cement, mineralization, material transport and railroad industries [4]. The casting structure of these steels includes carbides like as $(\mathrm{Fe}, \mathrm{Mn}) 3 \mathrm{C}$ which, by means of an adequate thermal treatment, could achieve a complete austenitic structure from these steels [5]. The traditional heat treatment for these steels that is annealing and cooling in a cold water bath. However, a completely austenitic structure without any carbide phase is desired, but such structures, particularly within coarse parts, are always unattainable [6].

The thermal conductivity of manganese-based austenitic steel is about 1.4 times and its thermal expansion coefficient is 1.5 times in relation to normal carbon steels, due to purpose, the rate/ratio of heating must be slow. Defined austenitization temperature from 950 to $1100^{\circ}$. After the retention time, the parts will cool in water. This heat treatment takes a long time to work, resulting in cost improvement [7]. Within the current research, to reduce the

Revised Manuscript Received on 14 September, 2019.

Arvind Kumar, Department of Mechanical Engineering, Sanskriti University, Uttar Pradesh, India.(Email: sanpubip@gmail.com) thermal treatment time \& at very moment obtain a completely austenitic structure, 5 different heat treatment cycles were chosen. Within these various methods, the mechanical/physical characteristics \& microstructure of the samples were investigated [8], [9].

\section{MATERIALS AND METHODS}

First, a foam model has been made as block Y. The smelting procedure has been done with chromite sands as a method for sodium silicate and $\mathrm{CO} 2$ gas. To avoid burns and obtain a high quality surface, a suitable coating material called Mold coat was used. Induction furnace was used to melt the steel. The first kiln charge was included in traditional steel scrap. The desired chemical composition has been controlled by ferroalloys. Figure 1 illustrates the chemical composition/configuration of the final sample analyzed by the Spectro-lab model quantifier. The heat treatment of the manganese samples was done in an electric furnace with 5 different cycles as illustrated in Figure 2 [10]-[12].

\begin{tabular}{|c|c|c|c|c|c|c|c|}
\hline $\mathbf{C}$ & $\mathbf{M n}$ & $\mathbf{S i}$ & $\mathbf{C r}$ & $\mathbf{N i}$ & $\mathbf{M o}$ & $\mathbf{P}$ & $\mathbf{S}$ \\
\hline 1.17 & 13.4 & 0.77 & 1.6 & 0.12 & 0.01 & 0.045 & 0.008 \\
\hline
\end{tabular}

Figure 1. Chemical composition/elements of steel (wt. $\%)$

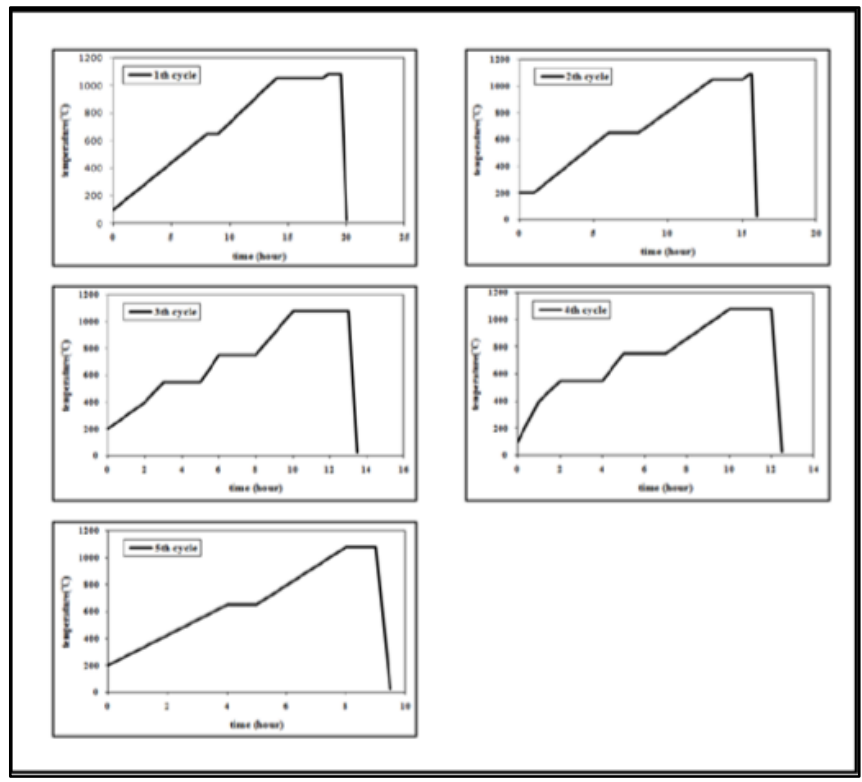

Figure 2. Five different heat treatment cycles 


\section{RESULTS AND DISCUSSION}

Figure 3 shows the microstructures of thermally treated samples. As it may be detected, in cycles 1 to 4 , the structure obtained is completely austenitic and desired. But within the 5th cycle, the resultant microstructure differs within the austenite grains and sometimes on its surface. It would happen when the austenitization time was not adequate or the temperature of the water high. Since the temperature of the water is constant for all the samples and only the cycles have been changed, it will be concluded that the carbides have not completely resolved within the austenite matrix, and that such a grain of glaze, such as carbides, has been maintained unresolved that caused the reduction of the beneficial life of the parts or sometimes their fracture.

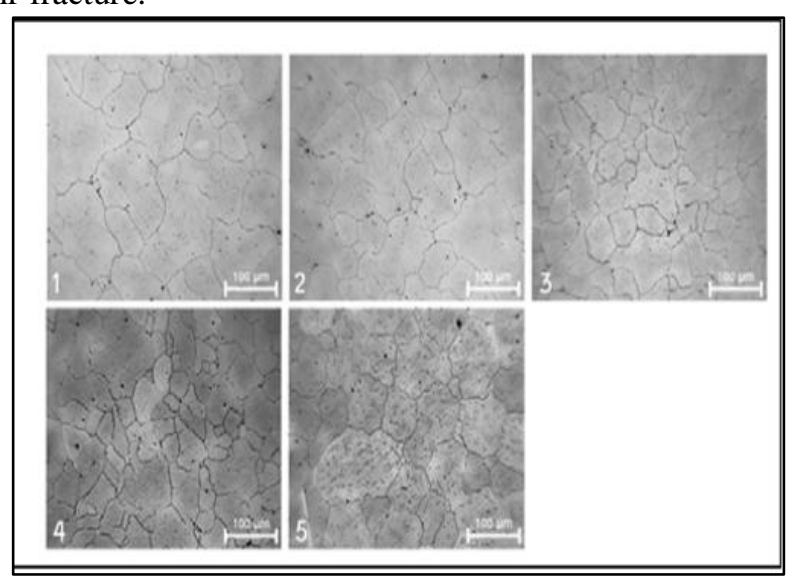

Figure 3. Different heat treatment cycles microstructures

Reduction of the useful life of the pieces, which means that these components of freezing have worked like hard micro particles and in the operation of use they cause the subsidence of surface and more wear and, consequently, pieces that reduce the life time. The amount of carbide measured in this cycle is 35 percent. Result of size of the grain of austenite is illustrated in Figure 4 and Figure 5. As can be seen, in cycles 3 and 4 , the size of the grain is appropriate and in other cycles the grain is thick.

\begin{tabular}{|c|c|c|c|c|c|}
\hline cycle & No. 1 & No. 2 & No. 3 & No. 4 & No. 5 \\
\hline ASTM grain size & 3 & $3-4$ & 5 & 5 & 4 \\
\hline
\end{tabular}

Figure 4. ASTM size of the grain of the austenite within different heat treatment cycles

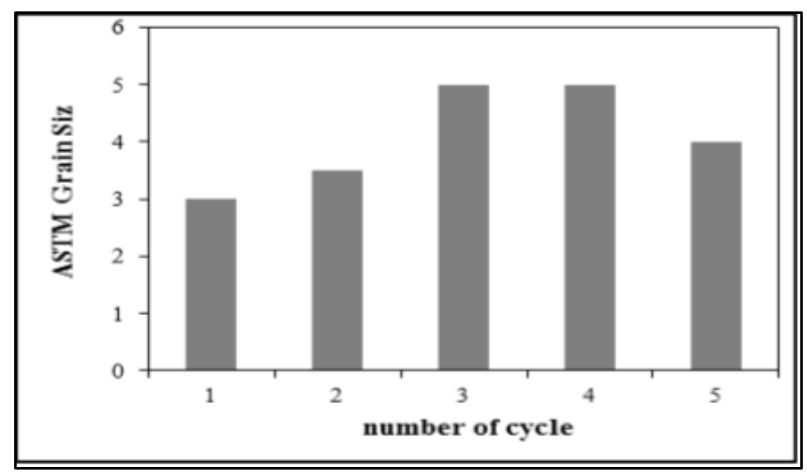

Figure 5. ASTM size of the grain of the austenite variates within diverse heat treatment cycles from other cycles and some ground grain could be observed

The results of the impact tests have been solved in Figure 6. Manganese steels will not normally break with impact and will only bend. The results gained from the impact tests of cycle 1 to 4 with a complete austenite structure, illustrate that, the samples have cracked from the indentation area and the curve, such a crack probably existed due to the hard work of the notch in the samples and within the 5th cycle, Fractured with lower impact energy in relation to the 4 samples mentioned.

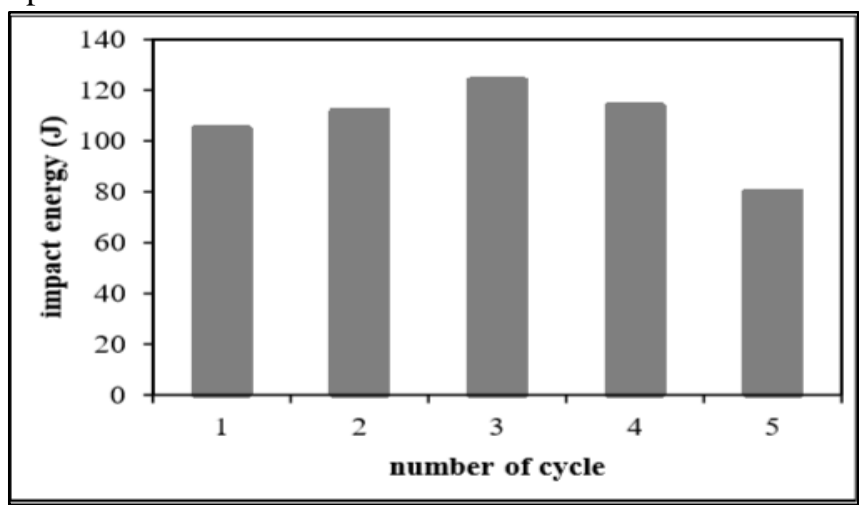

Figure 6. Impact energy variation within different heat treatment cycles

Making an allowance for the resulting microstructure and the impact tests on the samples obtained, the 4th cycle has been preferred due to time (economic aspect) and the desirable structure without carbide as the best thermal treatment cycle for austenitic manganese steels.

\section{CONCLUSION}

As the results of every test and experiment us shown in the graphical form, from the above results it can be concluded that $4^{\text {th }}$ cycle must be preferred over the others. The $4^{\text {th }}$ cycle is preferred due to time invested in this process is minimum and invested time always directly proportional to the economic aspects. The $4^{\text {th }}$ cycle is also preferred because the desirable structure without carbide as the best thermal treatment cycle for the austenitic manganese steels.

\section{REFERENCES}

1. R. W. Smith, A. Demonte, and W. B. F. Mackay, "Development of high-manganese steels for heavy duty cast-to-shape applications," J. Mater. Process. Technol., vol. 153, pp. 589-595, 2004.

2. M. B. Limooei and S. Hosseini, "OPTIMIZATION OF PROPERTIES AND STRUCTURE WITH ADDITION OF TITANIUM IN HADFIELD STEELS," 2012.

3. S. A. Torabi, K. Amini, and M. Naseri, "Investigating the Effect of Manganese Content on the Properties of High Manganese Austenitic Steels," 2017.

4. "Foundry - CBG." [Online]. Available: http://www.cbgsrl.it/en/foundry.html. [Accessed: 02-Jul2019].

5. D. Xiaodong, S. Guodong, W. Yifei, W. Jianfeng, and Y. Haoyu, "Abrasion Behavior of High Manganese Steel under Low Impact Energy and Corrosive Conditions," Adv. Tribol., vol. 2009, pp. 1-5, Nov. 2009. 
6. G.-F. Liang, C.-J. Song, X.-Y. Liu, J.-G. Li, and Z.-M. $\mathrm{Xu}$, "Eutectic decomposition in Ca-Si modified austenite medium Mn steel after solidification," J. Mater. Sci., vol. 40, no. 8, pp. 2081-2084, Apr. 2005.

7. "The impact toughness of iron manganese alloys."

8. A. Todić, A. Professor, D. Čikara, T. Todić, B. Pejović, and B. P. Student, "Ivica Čamagić Vukoje Vukojević The Influence of the Vanadium Content on the Toughness and Hardness of Wear resistant High-alloyed Cr-Mo Steel."

9. C. Haase, L. A. Barrales-Mora, C. Haase, and L. A. Barrales-Mora, "From High-Manganese Steels to Advanced High-Entropy Alloys," Metals (Basel)., vol. 9, no. 7, p. 726, Jun. 2019.

10. T. S. Wang, B. Lu, M. Zhang, R. J. Hou, and F. C. Zhang, "Nanocrystallization and $\alpha$ martensite formation in the surface layer of medium-manganese austenitic wear-resistant steel caused by shot peening," Mater. Sci. Eng. A, vol. 458, no. 1-2, pp. 249-252, Jun. 2007.

11. E. Curiel-Reyna et al., "Effect of Carbide Precipitation on the Structure and Hardness in the Heat-Affected Zone of Hadfield Steel After Post-Cooling Treatments," Mater. Manuf. Process., vol. 23, no. 1, pp. 14-20, Dec. 2007.

12. A. K. Srivastava and K. Das, "Microstructural characterization of Hadfield austenitic manganese steel," J. Mater. Sci., vol. 43, no. 16, pp. 5654-5658, Aug. 2008. 